\title{
RESPONSE OF ORAL MELPHALAN, PREDNISONE AND THALIDOMIDE (MPT) ON SYMPTOMATIC MULTIPLE MYELOMA PATIENTS WHO ARE NON- TRANSPLANT CANDIDATES
}

\author{
KAMRUZZAMAN M ${ }^{1}$, FERDOUS J ${ }^{2}$, ISLAM $\mathrm{S}^{3}$, KHAN MA ${ }^{4}$
}

\begin{abstract}
s
Background: Oral melphalan, prednisone and Thalidomide (MPT) has been tested and proved efficacy in multiple myeloma (MM). But, no data are available on the response rate and adverse effect of oral MPT in diagnosed symptomatic MM patients who are non-transplant candidates in our population and ethnic diversity. Here, we evaluated response rate and adverse effects of $M P T$.

Methods: 16 diagnosed symptomatic MM patients (age range 45-75 years) received MPT (Melphalan $4 \mathrm{mg} / \mathrm{m}^{2}$ divided dose and Prednisone $40 \mathrm{mg} / \mathrm{m}^{2}$ once daily for 7 days every month plus Thalidomide $100 \mathrm{mg} /$ day at night continuously) from January 2010 to December 2011 at department of Hematology, Dhaka medical college and hospital, Dhaka. After 3 courses of MPT, 2 patients had no improvement, so changed to another protocol. Rest 14 patients had completed 6 cycles of MPT and evaluated for both response rate and toxicity.

Results: The overall response rate (ORR) was $87.5 \%(n=14)$; complete response (CR) rate 50\% $(n=8)$, partial response $(P R)$ rate $31.25 \%(n=5)$, minimal response $(M R)$ rate $6.25 \%(n=1)$ and no response (NR) was $12.50 \%(n=2)$ of patients. During MPT therapy, MM patients noticed abdominal discomfort in $31.11 \%(n=14)$, insomnia in $17.78 \%(n=8)$, constipation in $13.33 \%(n=6)$, numbness/ peripheral neuropathy in $13.33 \%(n=6)$ and developed infection in $6.67 \%(n=3)$ and hyperglycaemia in $4.44 \%(n=2)$ of patients. Life threatening complications like DVT were absent. Almost all adverse effects were mild, reversible grade 1/2 toxicity and mostly developed within first cycle of MPT. Treatment related mortality was absent.
\end{abstract}

Conclusions: It clearly reveals MPT induces increase response rate with low cost and minimal side effects which might bring hope to the poor patients of our country.

Keywords: Multiple myeloma, MPT

J Dhaka Med Coll. 2016; 25(1) : 61-66

\section{Introduction:}

Myeloma cell is a malignant plasma cell which is derived from a post germinal centre B cell. Plasma cell infiltration in bone marrow results in bone marrow failure and bone lesions. Symptoms due to bone disease, hypercalcaemia, impaired haemopoiesis, immune paresis and renal failure. Plasmacytomas may spread extradurally or may cause spinal cord compression. High serum paraprotein may result in hyper viscosity and high levels of light chains (Bence-Jones protein) in the urine may result in renal failure.

\section{Treatment decisions:}

For an elderly patient with a recent diagnosis of symptomatic myeloma, the primary objective is to determine an appropriate treatment approach on the basis of biologic age, performance status, and co morbidities. The basic choice is between active therapy (most patients) and palliation (selected patients). Active therapy choices include stem-cell sparing induction therapy with a view to

1. Dr. Muhammad Kamruzzaman, Assistant Register (BMT Unit), Department of Hematology, DMCH.

2. Dr. Jannatul Ferdous, Assistant Professor, Department of Hematology, DMCH.

3. Dr. Sirajul Islam, Associate Professor, Department of Hematology, MMCH.

4. Prof. (Dr) Mohiuddin Ahmed Khan, Head of Department of Hematology \& BMT unit, DMCH.

Correspondence: Dr. Muhammad Kamruzzaman, Assistant Register (BMT Unit), Department of Hematology, DMCH. Email: kamruzzaman.sb29@gmail.com. Contact number: 01716344301.

Received: 01 March 2016

Accepted: 20 March 2016 
possible AHSCT. Palliation (selected patients) therapy choices include melphalan-prednisone with one of the novel agents, or other multidrug combinations. For example, there is evidence that MPV/VMP and MPL may overcome the adverse prognosis associated with certain high-

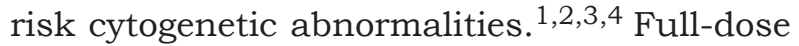
MPV/VMP and MPT can be administered safely in patients with renal failure, whereas lenalidomide needs dose adjustment. There is no risk of thrombosis with MPV/VMP, whereas this is a significant risk with MPT and MPL. MPV/VMP may be preferable in patients who have a history of thromboembolic phenomena. Bortezomib and thalidomide cause neuropathy, whereas lenalidomide does not. This is relevant in patients with diabetic neuropathy. All-oral regimen such as MPT, CTD, Thal-Dex, Len-Dex are more convenient than bortezomib-containing combination.

\section{Rationality:}

There is no cure for MM but there are many effective treatments that prolong and improve the quality of life ${ }^{5}$ such as chemotherapy and or bone marrow transplantation (BMT). Chemotherapy is the only treatment option who is non transplant candidates. Above all, our patients are very poor to bear the expenses of BMT. Among the chemotherapy regimen, MPT is available oral and reasonable economic and cost effective immunomodulatory therapy without hospitalization. Bortezomib/ Lenalidomide is costly drugs than MPT. Low dose of oral MPT has no known direct myelosuppressive effect. So it attempted to find out increased response rate with cheapest drug and minimal complications. Complete remission (CR) was an important goal irrespective of sex and age e"45 years. Prolongation of remission and survival are additional goals.

\section{Thalidomide as Maintenance Therapy:}

Several trials are evaluating the tolerability of thalidomide as maintenance. ${ }^{6,7,8}$ Finally, the question that ultimately needs to be addressed is whether salvage therapy will be as good as maintenance therapy.

\section{Methodology:}

Total $30 \mathrm{MM}$ patients attended in outpatients and indoor patients department, among them
5 cases were excluded as per study selection criteria. In the rest 25 patients; 9 patients $(6$ new and 3 old) were dropped out from this study. So, finally my sample size was 16 for this prospective observational study.

\section{Selection criteria:}

Inclusion criteria: diagnosed patients with symptomatic MM who are non-transplant candidates. Age: $\geq 45$ years. Performance status scale (ECOG): 0-4 (all), Expected survival: > 6 months. Pretreatment laboratory value: Platelet count: $\geq 100 \times 10^{9} / \mathrm{L}$, Absolute neutrophil count: $>1000 \times 10^{9} / \mathrm{L}, \mathrm{S}$. Creatinine $:<3 \mathrm{mg} / \mathrm{dl}$, Corrected S. calcium $:<14 \mathrm{mg} / \mathrm{dl}$ (<3.5 m mol/L).

Exclusion criteria- 1) Smoldering or indolent myeloma 2) Any history of hypersensitivity to component of MPT 3) Peripheral neuropathy 4) Uncontrolled or severe cardiovascular disease 5) Sepsis 6) Pregnancy and breast feeding and 7) Uncontrolled diabetes.

After fulfilling the criteria for entry into this study oral MPT were given (28days $\times 6$ cycles).

- Melphalan=4mg/ $\mathrm{m}^{2}$ divided dose Day 1 to 7 ;

- Prednisolone $=40 \mathrm{mg} / \mathrm{m}^{2}$ single dose at morning Day 1 to 7 ;

- Thalidomide $=100 \mathrm{mg} /$ day at night continue.

All patients were treated with MPT in outpatients department (OPD). Anti-platelet drug (to prevent the risk of thromboembolism), antibiotic (for infection) and red cell concentrate transfusion (if haemoglobin less than $8 \mathrm{gm} / \mathrm{dl}$ ) were given as necessary. Most of the patients received variable number of zoledronic acid.

\section{Assessment of responses:}

Both bone marrow study and S. protein electrophoresis were done to assess response after $3 \mathrm{rd}$ and 6 th cycle of MPT. As immunofixation test is expensive and not available in $\mathrm{DMCH}$, we used the European Group for Blood and Marrow Transplantation (EBMT) criteria for responses to anti-myeloma treatment in this study. 
Observations and result:

Table 3.1

Age distribution of the study population $(n=16)$

\begin{tabular}{lcc}
\hline $\begin{array}{l}\text { Age } \\
\text { (Range 45-75 years) }\end{array}$ & $\begin{array}{c}\text { Number of } \\
\text { patients }\end{array}$ & $\begin{array}{c}\text { Percentage } \\
(\%)\end{array}$ \\
\hline $45-50$ & 5 & 31.25 \\
$51-55$ & 2 & 12.50 \\
$56-60$ & 2 & 12.50 \\
$61-65$ & 3 & 18.75 \\
$66-70$ & 2 & 12.50 \\
$71-75$ & 2 & 12.50 \\
\hline Total & 16 & 100.00 \\
\hline
\end{tabular}

Table 3.2

Clinical presentations of study population before MPT therapy $(n=16)$.

\begin{tabular}{lcc}
\hline Presentations & $\begin{array}{c}\text { Number of } \\
\text { patients }\end{array}$ & $\begin{array}{c}\text { Percentage } \\
(\%)\end{array}$ \\
\hline Weakness and fatigue & 16 & 38.09 \\
Low back pain & 9 & 21.42 \\
Fever & 6 & 14.28 \\
Body ache & 2 & 4.76 \\
Per rectal bleeding & 2 & 4.76 \\
Leg swelling & 2 & 4.76 \\
Joint pain & 1 & 2.38 \\
Weight loss & 1 & 2.38 \\
Chest pain & 1 & 2.38 \\
Left sided weakness & 1 & 2.38 \\
Palpitation & 1 & 2.38 \\
\hline
\end{tabular}

Table 3.3

Clinical findings (number $=16$ )

\begin{tabular}{lcc}
\hline Signs & Numbers & $\begin{array}{c}\text { Percentages } \\
(\%)\end{array}$ \\
\hline Anaemia & 14 & 77.78 \\
Edema & 2 & 11.11 \\
Hemi paresis & 1 & 5.55 \\
Hepatomegaly & 1 & 5.55 \\
\hline
\end{tabular}

Table 3.4

Co-morbidity of the study population $(n=16)$.

\begin{tabular}{lcc}
\hline Co-morbidity & $\begin{array}{c}\text { Number of } \\
\text { patients }\end{array}$ & $\begin{array}{c}\text { Percentage } \\
(\%)\end{array}$ \\
\hline Renal impairment & 9 & $36 \%$ \\
RTI & 6 & $24 \%$ \\
Arthritis & 1 & $4 \%$ \\
CVD & 1 & $4 \%$ \\
Diabetes & 1 & $4 \%$ \\
HBsAg positive & 1 & $4 \%$ \\
\hline
\end{tabular}

Table 3.5

Distribution of the study population according to previous treatment ( $n=8$ out of 16 )

\begin{tabular}{lcc}
\hline Previous treatment & $\begin{array}{c}\text { Number of } \\
\text { patients }\end{array}$ & $\begin{array}{c}\text { Percentage } \\
(\%)\end{array}$ \\
\hline $\begin{array}{l}\text { Previous treatment } \\
\text { with VAD }\end{array}$ & 5 & 62.50 \\
$\begin{array}{l}\text { Previous treatment with } \\
\text { MP- } 6 \text { cycles }\end{array}$ & 1 & 12.50 \\
$\begin{array}{l}\text { Previous treatment with } \\
\text { MPCV- } 4 \text { cycles }\end{array}$ & 1 & 12.50 \\
$\begin{array}{l}\text { Previous treatment } \\
\text { with Thal-dex- } 1 \text { cycle }\end{array}$ & 1 & 12.50 \\
\hline
\end{tabular}

Serum protein electrophoresis: All study population had monoclonal band before treatment with MPT. After completion of 3 cycles of MPT, no changes of monoclonal band in $12.5 \%(n=2)$ of patients (NC/NR). Rest $87.5 \%$ $(\mathrm{n}=14)$ of MM patients, disappear monoclonal band in $50 \%(n=8)$ of patients $(\mathrm{CR})$ and faint band in $37.5 \%(n=6)$ of patients after completion of 6 cycles of MPT $\{>50 \%$ reduction of monoclonal protein in $31.25 \%(n=5)$ of patients (PR) and $<49 \%$ reduction of monoclonal protein in $6.25 \%(n=1)$ of patients $(M R)\}$.

Percentage of bone marrow plasma cells: Among 16 patients, $>30 \%$ to sheets of $\mathrm{BM}$ plasma cells were in $93.75 \%(n=15)$ of MM patients and only $6.25 \%(n=1)$ of patients had $<10 \%$ BM plasma cells before treatment with MPT. After completion of 3 cycles of MPT, no changes of BM plasma cells (>50\% BM plasma cells) in $12.5 \%$ $(n=2)$ of patients (NR). Rest $87.5 \%(n=14)$ of patients continue MPT and after completion of 6 cycles, BM plasma cells $<5 \%$ in $50 \%(n=8)$ and $5-10 \%$ BM plasma cells in $37.5 \%(n=6)$ of patients $\{31.25 \%(n=5)$ patients achieved PR and $6.25 \%$ $(\mathrm{n}=1)$ patients achieved MR)\}. 
Table: $\mathbf{3 . 6}$

Haematological and biochemical findings of the study populations before MPT.

\begin{tabular}{lccc}
\hline Parameters & Value & Numbers of patient & Percentages \\
\hline ESR $\left(\mathrm{mm}\right.$ in $\left.1^{\text {st }} \mathrm{hr}\right)$ & $>100$ & 14 & 87.50 \\
& $<100$ & 2 & 12.50 \\
Total & $<6$ & 16 & 100.00 \\
$\mathrm{Hb}(\mathrm{gm} / \mathrm{dl})$ & $6-9$ & 3 & 18.75 \\
& $9-11$ & 10 & 62.50 \\
Total & $>12$ & 16 & 18.75 \\
Calcium $(\mathrm{mg} / \mathrm{dl})$ & $<12$ & 2 & 100.00 \\
& & 10 & 16.66 \\
Albumin $(\mathrm{gm} / \mathrm{dl})$ & $>3.5$ & Total=12 & 83.33 \\
& $>3.5$ & 9 & 100.00 \\
Total & 15 & 6 & 60.00 \\
& & 100.00 & 40.00 \\
$\mathrm{~B}_{2}-$ micro globulin $(\mathrm{mg} / \mathrm{L})$ & $<3.5$ & 5 & 41.66 \\
& $3.5-5.5$ & 2 & 16.66 \\
& $>5.5$ & 5 & 41.66 \\
\hline Total & & 12 & 100.00 \\
\hline
\end{tabular}

Bony Lytic lesion: In this study, 87.5\% (14) of patients had bony lytic lesion and absent in $12.5 \%$ (2) of MM patients.

Table-3.6

Responses observed after 6 cycles of MPT therapy $(n=16)$

\begin{tabular}{|c|c|c|c|c|c|c|}
\hline \multirow{2}{*}{$\begin{array}{l}\text { Response } \\
(\mathrm{N}=16)\end{array}$} & \multicolumn{2}{|c|}{ New $(\mathrm{N}=8)$} & \multicolumn{2}{|c|}{ Old $(\mathrm{N}=8)$} & \multirow[t]{2}{*}{ Total } & \multirow[t]{2}{*}{ Percentages } \\
\hline & Stage-IIIA & Stage-IIIB & Stage-IIIA & Stage-IIIB & & \\
\hline $\mathrm{CR}$ & 3 & 3 & 0 & 2 & 8 & 50.00 \\
\hline$\overline{\mathrm{PR}}$ & 1 & 0 & 2 & 2 & 5 & 31.25 \\
\hline MR & 0 & 0 & 1 & 0 & 1 & 6.25 \\
\hline NR & 0 & 1 & 1 & 0 & 2 & 12.50 \\
\hline Total & & 16 & 100 & & & \\
\hline
\end{tabular}

Table: 3.7

Complications/Side effects of MPT during therapy $(n=16)$

\begin{tabular}{lcc}
\hline Side effect & Number & Percentages (\%) \\
\hline Abdominal discomfort & 14 & 31.11 \\
Insomnia & 8 & 17.78 \\
Constipation & 6 & 13.33 \\
Numbness/Peripheral neuropathy & 6 & 13.33 \\
Infection & 3 & 6.67 \\
Hyperglycemia & 2 & 4.44 \\
DVT & nil & 0.00 \\
\hline
\end{tabular}




\section{General discussion:}

As I planed initially to continue MPT up to 6 months; only 14 patients continued MPT in this duration. Total $30 \mathrm{MM}$ patients were attended in outpatients and indoor patients department from January 2010 to December 2011. Initially around $60 \%$ of patients were admitted in internal medicine, $15 \%$ in neurosurgery, $15 \%$ in nephrology and 5\% orthopedic ward and were transferred to OPD department of Hematology. Among them 5 cases were excluded as per study selection criteria. Among the rest 25 patients 20 were male and 5 were female. Male: female ratio was $4: 1$. 14 were new and 11 were old patients. 9 patients $(6$ new and 3 old; male $=5$, female=4) were dropped out. Every patient contact number had collected. If any patients not come to follow up, asked them with proper counseling for follow up. Causes of dropped out were 1). No follow up of 6 patients $(\mathrm{M}=3 ; \mathrm{F}=3)$ due to negligence, ignorance, economical and transport problems, 2). One male patient went to abroad and 3). Two patients $(\mathrm{M}=1, \mathrm{~F}=1)$ died at home within $1^{\text {st }}$ cycle of MPT, of them one female patient died due to diarrhea and another male died due to respiratory tract infection. So, finally my sample size was $16(\mathrm{M}=15 ; \mathrm{F}=1)$ for this prospective observational study. Two patients discontinued treatment at $4^{\text {th }}$ cycle of MPT due to no change both in BM study and S. protein electrophoresis as they were non responders. No patient had in progressive disease.

This study shows MPT was generally welltolerated. The overall response rate (ORR) was $87.5 \%(n=14)$; complete response $(\mathrm{CR})$ rate $50 \%$ $(\mathrm{n}=8)$, partial response $(\mathrm{PR})$ rate $31.25 \%(\mathrm{n}=5)$, minimal response $(\mathrm{MR})$ rate $6.25 \%(\mathrm{n}=1)$ and no response (NR) was $12.50 \%(\mathrm{n}=2)$ of patients. During MPT therapy, MM patients complaints abdominal discomfort in $31.11 \%(n=14)$, insomnia in $17.78 \%(\mathrm{n}=8)$, constipation in $13.33 \% \quad(n=6), \quad$ numbness / peripheral neuropathy in $13.33 \%(\mathrm{n}=6)$ and developed infection in $6.67 \%(n=3)$ and hyperglycaemia in $4.44 \%(n=2)$ of patients. Life threatening complications like DVT were absent. Almost all adverse effects were mild, reversible grade $1 / 2$ toxicity and mostly developed within first cycle of MPT. Treatment related mortality was absent. However, MPT can also cause DVT, myelosuppression which can be severe enough to kill the patient, though uncommon. So, early referral and prompt intensive treatment is essential to improve the treatment outcome. Bone lytic lesion, hepatomegaly and HBsAg positive patients are found to be risk factors. Finally, treatment cost analysis reveals MPT is cheaper oral therapy and easily available in our country. Total cost of 6 cycles of MPT is approximately 1500-2000 Tk.

\section{Conclusions}

The major limitation to our study was no regular follow up due to ignorance, economical and transport problems in spite of proper counseling. We had conducted this study at a single centre only for two years. Our sample size was also small. To make the study result more authentic and widely acceptable, we recommend conducting a multi center based trial on the effectiveness of MPT. A case control comparative study (with MPV, MPL, CTD, Thaldex or Len-dex) is recommended to see superiority of oral MPT over other second line drugs used in diagnosed symptomatic multiple myeloma patients who are non-transplant candidates in the back ground of low cost with optimum responses and minimal side effects in our contest. We hope that long term follow up will enrich our knowledge.

\section{References}

1. Osserman EF, Takatsuki $\mathrm{K}$ and Talal N. The pathogenesis of "amyloidosis." Semin Hematol $1964 ; 1: 3-85$.

2. Mateos MV, Richardson PG, Schlag R, et al. Bortezomib plus melphalan and prednisone compared with melphalan and prednisone in previously untreated multiple myeloma: updated follow-up and impact of subsequent therapy in the phase III VISTA trial. J Clin Oncol. 2010;28(13):2259-2266.

3. Palumbo A, Falco P, Corradini P, et al. Melphalan prednisone, and lenalidomide treatment for newly diagnosed myeloma: a report from the GIMEMAItalian Multiple Myeloma Network. J Clin Oncol. 2007;25(28):4459-4465.

4. Kapoor P, Kumar S, Fonseca R, et al. Impact of risk stratification on outcome among patients with multiple myeloma receiving initial therapy with lenalidomide and dexamethasone. Blood. 2009; $114(3): 518-521$. 
5. John P. Greer, John Foerster, George M. Rodgers, Frixos Paraskevas, Bertil Glader, Daniel A Arber, et al. Wintrobe's clinical hematology, $12^{\text {th }} \mathrm{ed}$, Lippincott Williams \& Wilkins, Philadelphia USA, 2009, P. 2372-2438.

6. Brinker BT, Waller EK, Leong T, et al. Maintenance therapy with thalidomide improves overall survival after autologous hematopoietic progenitor cell transplantation for multiple myeloma. Cancer 2006; 106:2171-2180.
7. Gonzalez F, Trujillo JM, Alexanian R. Acute leukemia in multiple myeloma. Ann Intern Med 1977;86:440-443.

8. Bergsagel DE, Bailey AJ, Langley GR, et al. The chemotherapy on plasma-cell myeloma and the incidence of acute leukemia. N Engl J Med 1979;301:743-748.

9. Palumbo A, Bertola A, Musto P, Caravita T, Callea V, Nunzi M, Grasso M, Falco P, Cangialosi C, Boccadoro M.Cancer. 2005 Oct 1; 104(7):142833. 